\title{
A Imagem Feminina de Moscou na Literatura Russa
}

\author{
Edelcio Américo ${ }^{1}$
}

\begin{abstract}
The present article deals with one aspect of the correlation between the two Russian capitals, Moscow and Saint Petersburg, i.e.: the female image of Moscow and, therefore, the male character of Saint Petersburg, that graduated in the Russian literature and culture and their transformations over the XVIII-XX centuries. As examples, we will use some works of Russian classics such as Aleksandr Pushkin, Leo Tolstoy and Nikolai Gogol, among others.
\end{abstract}

Keywords: Moscow; Saint Petersburg; Russian literature; city; bicentrism.

Resumo: O presente artigo visa a abordar um dos aspectos da correlação entre as duas capitais russas, Moscou e São Petersburgo, ou seja: a imagem feminina de Moscou e, por conseguinte, o caráter masculino de São Petersburgo, que se formaram na literatura e na cultura russa, bem como as suas transformações ao longo dos séculos XVIII-XX. Como exemplos, recorreremos a obras de clássicos russos como Aleksandr Púchkin, Liev Tolstói e Nikolai Gógol, entre outros.

Palavras-chave: Moscou; São Petersburgo; literatura russa; cidade; bicentrismo.

\section{Introdução}

A discussão envolvendo as duas capitais russas, Moscou e São Petersburgo, prolonga-se há pelo menos três séculos. As relações entre essas cidades tornaram-se fato objetivo da história russa desde a fundação da nova capital, às margens do Rio Nevá, e atingiram todos os segmentos do desenvolvimento histórico-cultural da Rússia e da formação da identidade nacional do país. De fato, a partir desse momento, na cultura russa começaram a se formar divergências essenciais entre a nova e a velha capital, que representavam dois conceitos políticos e fixavam dois tipos culturais.

A cidade de São Petersburgo, criada por Pedro, o Grande, em 1703, tinha o intuito de europeizar a Rússia, cujo atraso tecnológico e cultural em relação aos países ocidentais incomodava ao czar. A partir de então, Moscou passou a ser vista como a representação da "velha" Rússia, da sua origem, suas tradições e superstições; já São Petersburgo, sendo uma cidade europeia, era o símbolo do progresso. Desse modo, as duas capitais, a antiga e a nova, formaram uma oposição cultural.

A contraposição cultural das duas cidades definiu-se e agravou-se principalmente ao longo do século XIX, quando se iniciou o desenvolvimento de um olhar crítico da Rússia sobre si mesma. Nesse período, as questões filosóficas referentes

\footnotetext{
${ }^{1}$ Doutor em Literatura e Cultura Russa pela Faculdade de Filosofia, Letras e Ciências Humanas da Universidade de São Paulo (FFLCH/USP).
} 
ao futuro do país passaram a ser discutidas nas obras literárias, como, por exemplo, nos romances de Nikolai Gógol, Fiodor Dostoiévski, Ivan Turguiénev e Liev Tolstói, entre outros.

Desde o início, Petersburgo foi pensada como uma concretização da ideia da cidade "correta", surgida no pensamento europeu desde o Renascimento. A contraposição com Moscou, uma cidade "russa e natural", tornou-se óbvia. Entretanto, não seria correto afirmar que o fenômeno do "bicentrismo" da cultura russa teve seu início com a construção de São Petersburgo, pois a Rússia antiga, antes da primazia de Moscou, também possuía dois polos: Kiev, ao sul, e Nóvgorod, ao norte. O bicentrismo é uma característica essencial da cultura russa e representa um modelo universal da cultura humana por estar presente nas principais oposições arquetípicas, como o Bem e o Mal, Deus e o Diabo, o Direito e o Esquerdo, o Homem e a Mulher, e assim por diante. A presença das oposições binárias, como característica do pensamento universal, origina-se, antes de tudo, na divisão do cérebro humano em dois hemisférios.

Na Rússia, diversos autores dedicaram seus estudos ao problema das relações culturais entre Moscou e Petersburgo. Principalmente esse assunto foi desenvolvido pelos pesquisadores integrantes da Escola Semiótica de Tártu-Moscou, também chamada de Escola Semiótica Russa. Entre eles, destacam-se os trabalhos de Iúri Lótman (Lótman, 2002), Vladímir Toporov (Toporov, 2003) e Serguei Nekliúdov (Nekliúdov, 2005), que desenvolveram o conceito de "cidade como um texto" e o aplicaram às duas capitais russas. O ensaio de Serguei Nekliúdov "O Corpo de Moscou: a Questão da Imagem da 'Cidade-Mulher' na Literatura Russa” serviu como base teórica para a elaboração do presente artigo.

Já no Brasil, a correlação cultural entre Moscou e São Petersburgo é praticamente desconhecida. Existem apenas as traduções de alguns livros que abordam o tema, como, por exemplo, Petersburgo, de Solomon Vólkov (Vólkov, 1997), e Tudo que É Sólido Desmancha no Ar, de Marshall Berman (Berman, 2010).

\section{Moscou como mulher}

Um dos aspectos das relações conturbadas entre as duas cidades, a ser abordado no presente artigo, é a sua ligação com o princípio de masculino e feminino. Essa caracterização é motivada, antes de qualquer coisa, pelo nome das cidades: Moscou (Moskvá, em russo) é uma palavra do gênero feminino, enquanto São Petersburgo, do 
gênero masculino. Essa é a razão principal de Moscou ser percebida na cultura russa como dotada de traços femininos e Petersburgo, de traços masculinos, fato que, além da rivalidade, gera entre ela e Petersburgo relações de mãe e filho, irmã e irmão, noiva e noivo.

Essas correlações entre as duas capitais russas são refletidas em muitos provérbios russos, como, por exemplo: "Moscou é a mãe de todas as cidades", "Mãezinha Moscou de pedra branca, de cúpulas douradas, hospitaleira, ortodoxa e faladeira", "Petersburgo quer casar, mas Moscou recusa", e assim por diante.

Desde os tempos mais remotos, o homem associava a Terra à imagem feminina, materna; em muitas culturas, existem divindades femininas que personificam a Mãe Terra. Provavelmente, a mais conhecida delas é a deusa grega Gaia. Não é por acaso que em muitas línguas as palavras "terra" e "país" pertençam ao gênero feminino.

Com a urbanização da cultura humana, essa característica feminina foi transferida para a cidade, que também é uma palavra do gênero feminino, por exemplo, em português. Embora em russo a palavra cidade, górod, pertença ao gênero masculino, muitos dos topônimos entre as cidades russas são femininos, basta lembrar Moscou (Moskvá), Samara, Vologda, Riazan, etc. Entre os nomes de países, muitos também são do gênero feminino: Rússia, Inglaterra, Alemanha, França e assim por diante. De acordo com a estudiosa de literatura e cultura Olga Fréidenberg:

A divindade local mais tarde torna-se a divindade de todos os povoados e, com o desenvolvimento da produção, a divindade da cidade; por isso, nas línguas antigas, entre elas a hebraica e a grega, cidade é pertencente ao gênero feminino (Fréidenberg, 1978, p. 495).

Na opinião de Serguei Nekliúdov (Nekliúdov, 2005), a imagem de Nossa Senhora, padroeira de muitas cidades, também pode ser vista nesse contexto. Por exemplo, na Rússia antiga, ela era a padroeira e defensora das cidades mais importantes, como Nóvgorod, Kiev e Moscou.

Ainda segundo Nekliúdov, no folclore, as cidades muitas vezes são comparadas às noivas, viúvas, mães: elas podem se casar, e as noivas sofrem assédio e são tomadas como se fossem cidades. Nas palavras de Olga Fréidenberg:

Se uma cidade, assim como a terra, era vista como uma mulher, e a divindade que estava casando entrava na cidade, essa entrada, em razão 
do pensamento concreto, já simbolizava o ato sexual; ao entrar na cidade era como se o deus a fecundasse (Fréidenberg, 1978, p. 497).

Curiosamente, esse motivo folclórico de tomada da cidade comparada à conquista de uma mulher aparece no romance Guerra e Paz, de Liev Tolstói, quando Napoleão, como resultado da tentativa de conquistar a Rússia em 1812, finalmente se vê diante da tão desejada Moscou:

E daquele ponto de vista ele contemplava a beldade oriental até então nunca vista e que jazia à sua frente. Para ele mesmo era estranho que, por fim, tivesse realizado seu desejo mais antigo, que lhe parecia impossível. $\mathrm{Na}$ luz clara da manhã, Napoleão olhava ora a cidade, ora o mapa, examinando detalhes daquela cidade, e a certeza da posse o perturbava e o assustava (Tolstói, 2011, p. 1806).

Segundo relatos dos contemporâneos da época, o próprio Napoleão dizia: "Uma capital tomada por um adversário parece uma mulher que perdeu sua honra: faça o que quiser é impossível devolver a sua honra" (Gúlin, 2000, p. 160).

Além da alegria de um conquistador, Napoleão, assim como o seu exército, sentiu que a sua missão era levar civilização a essa cidade que misturava Ásia e Europa:

"Estranha, bela, majestosa cidade! E que estranho e majestoso é esse minuto! [...] Mas, não, não, é verdade que estou em Moscou" - passoulhe pela cabeça de repente. "Todavia aí está ela, deitada aos meus pés, rebrilhando e brandindo suas cúpulas douradas e suas cruzes aos raios do sol. Mas vou poupá-la. Nos ancestrais monumentos da barbárie e do despotismo, inscreverei grandiosas palavras de justiça e misericórdia... [...] Do alto do Krémlin, sim, lá está o Krémlin, sim, darei a eles leis de justiça, mostrarei a eles o sentido verdadeiro da civilização, obrigarei gerações de boiardos a recordar com amor o nome do seu conquistador" (Tolstói, 2011, p. 1807).

Para desgosto de Napoleão, porém, a Moscou conquistada foi abandonada por seus habitantes. Considerando o significado mitológico da entrada na cidade, é muito expressivo o fato de, no romance, o imperador francês decidir não entrar na cidade, e sim parar em uma hospedaria nos arredores.

Já nas primeiras descrições de Moscou feitas por Tolstói, ela aparece como um ser capaz de sentir: 
Do alto da colina Poklónaia, Moscou se estendia ampla, com seu rio, seus bosques e igrejas, e parecia viver sua vida, palpitante com suas cúpulas como estrelas sob os raios do sol (Tolstói, 2011, p. 1805).

Aos poucos se torna evidente que, além de viva, a cidade é uma "mulher":

Todo russo, ao contemplar Moscou, sente que ela é uma mãe; todo estrangeiro, ao contemplá-la, ignorando seu significado maternal, não pode deixar de sentir o caráter feminino da cidade, e Napoleão sentiu isso (Tolstói, 2011, p. 1805).

Como podemos observar, as relações entre o conquistador e a cidade desenvolvem-se da seguinte forma:

$\mathrm{Na}$ primeira delas, a cidade de Moscou rejeitava o "líder do Império francês" Napoleão Bonaparte; na segunda surgiram imagens de Moscou como mãe e de Napoleão como conquistador, com sua ideia referente à "beldade oriental", porém Moscou não aceitava os abraços do novo Tamerlão e o conquistador fora derrotado; finalmente, na terceira dimensão, é possível associar a imagem de Moscou com a casa de Nossa Senhora, e a imagem de Napoleão com um anti-herói precursor do Anticristo. Nessa oposição, a escuridão era vencida pela luz e Bonaparte saía dela completamente humilhado (Gúlin, 2000, p. 166).

Resumindo, no romance Guerra e Paz, por um lado, Moscou aparece como uma mulher diante do seu conquistador, Napoleão, e, por outro, representa uma figura materna: mãe de todas as cidades, ou seja, de toda a Rússia.

Entre os escritores russos, não foi apenas Tolstói que abordou esse tema. Provavelmente, fora do contexto folclórico, pela primeira vez o motivo da comparação entre Moscou e uma mulher aparece no texto "Petição de Moscou referente ao seu esquecimento", escrito ainda no século XVIII (1787) pelo príncipe russo Mikhail Scherbátov à imperatriz Ekaterina II, com o objetivo de convencê-la a não esquecer Moscou em detrimento de São Petersburgo. Descrevendo a lamentável situação de abandono de Moscou após a transferência da capital para São Petersburgo, Scherbátov, em nome da primeira capital russa, confessa que "fontes de lágrimas, como as de uma viúva, escorriam dos meus olhos" (Américo, 2011, p. 201).

Na novela de Karamzín Natália, a Filha do Boiardo (Natália, Boiárskaia Dotch), de 1792, Moscou também é comparada a uma moça jovem e bonita: 
Natália [...] se aproximava da janela redonda de sua casa alta para contemplar a maravilhosa imagem da natureza que despertava: olhar para a Moscou de cúpulas douradas da qual o dia luminoso tirava o nebuloso véu da noite e que, como um pássaro enorme, acordado pela voz de amanhecer, tirava de si o orvalho brilhante. [...] "Como é bela a Moscou de pedra branca! Como são belos os seus arredores!” Mas, o que a Natália não pensava é que ela mesma, com suas vestimentas matutinas, era a mais bela de tudo (Américo, 2011, p. 117).

Ainda em 1792, Nikolai Karamzín publicou a novela A Pobre Liza, e, em 1809, Vladímir Jukóvski escreveu O Arvoredo de Maria (Márina Rosha). Os acontecimentos na novela de Karamzín são contemporâneos à época em que foi escrito, enquanto o drama de Jukóvski tem como pano de fundo uma época anterior à fundação de Moscou. Em ambas as novelas, as heroínas principais morrem: Liza comete suicídio ao saber que seu amado a traiu e Maria é assassinada. O corpo das moças, em ambos os casos, é lançado nas águas: no lago próximo ao Mosteiro Símonov e no Rio Iáuza.

Posteriormente, o motivo "trágico-amoroso" relacionado a Moscou foi desenvolvido em várias obras. Em Gore ot Uma, de Griboiédov, Tchátski sofre por um amor não correspondido. Aleksandr Púchkin faz com que seu protagonista Evguiéni Oniéguin primeiro recuse o amor de Tatiana e depois seja recusado por si mesmo. Por amor, Anna Kariênina se joga embaixo de um trem em uma estação nos arredores de Moscou. Doutor Jivago não encontra felicidade com sua amada Lara... A lista poderia ainda ser mais extensa, porém, mediante tais acontecimentos, surge outro tema que carece de discussão: seria possível o amor com final feliz na literatura russa?

Além da metáfora de uma mulher jovem, muitos dos escritores russos do século XIX descrevem Moscou como uma velha ou viúva. Em comparação com a nova capital em desenvolvimento, Moscou "começou a ser percebida como mais arcaica do que era" (Iussúpov, 2000, p. 10). Essa ideia foi claramente enunciada por Aleksandr Púchkin, que, em seu artigo "Viagem de Moscou para Petersburgo", afirma:

A decadência de Moscou é uma consequência inevitável da elevação de Petersburgo. As duas capitais não podem igualmente florescer dentro do mesmo Estado, assim como dois corações não coexistem no corpo humano (Américo, 2011, p. 67).

Em "O Cavaleiro de Bronze", Púchkin chama Moscou de "viúva de manto púrpuro". Já que o manto púrpuro era a regalia dos monarcas, nessa metáfora Moscou é apresentada como a esposa do monarca que perdeu o seu marido. 
Já São Petersburgo, desde o momento de sua criação, foi relacionada ao nome de Pedro, o Grande, e, por conseguinte, à figura masculina. Seguindo essa linha associativa, Nikolai Gógol desenvolveu a comparação entre Moscou e Petersburgo no plano da confrontação das características masculinas e femininas:

Moscou é uma velha caseira, faz panquecas, olha de longe e escuta a história sobre o que acontece no mundo sem se levantar das poltronas; Petersburgo é um rapaz desembaraçado, nunca fica em casa, sempre está vestido, passeia na fronteira e se atavia diante da Europa, a qual vê, mas não ouve. [...] Moscou é do gênero feminino, São Petersburgo - do masculino. Em Moscou, todas são noivas; em São Petersburgo, todos são noivos (Américo, 2011, p. 215-216).

Em seguida, o paralelo "homem-mulher" é desenvolvido pelo autor no sentido da oposição tradicional entre as duas capitais, na qual Moscou representa o universo tradicional e São Petersburgo simboliza a aspiração do país rumo à Europa:

Petersburgo é um homem ordenado, um alemão completo, olha para tudo fazendo contas, e, antes de dar uma festa, olha para o bolso; Moscou é uma nobre russa, e se ela se diverte, faz isso até cair e não se preocupa se vai gastar mais do que tem no bolso: ela não gosta de meio-termo (Américo, 2011, p. 216).

Moscou representa a fertilidade feminina, sendo uma característica extremamente positiva: "Moscou é necessária para a Rússia; Petersburgo precisa da Rússia”. No entanto, para Gógol existe o outro lado dessa personagem: ela não é só fértil, generosa e acolhedora, mas também é uma mulher desmazelada e despenteada, enquanto São Petersburgo é um "janota" de "sobrecasaca de flanela". Dessa forma, o que inicialmente se mostra como uma imagem positiva torna-se negativa e vice-versa. A amplitude e desinibição de Moscou estão no limiar do relapso e o pedantismo de São Petersburgo torna-se uma autodisciplina:

Moscou pandega até quatro horas da madrugada e no dia seguinte não levanta da cama antes de uma e pouco; Petersburgo também farreia até as quatro, porém no dia seguinte, como se nada tivesse acontecido, apressase, com sua sobrecasaca de flanela, para a repartição pública (Américo, 2011, p. 216).

Apesar de representarem opostos, as duas capitais também se completam e não conseguem existir uma sem a outra. Isso é revelado no modo como a antiga capital se 
refere à nova: tratamento de mãe para com o filho: "Correr sete verstas para longe da mamãe! Mas que ágill!”. Ou então: “Em Moscou, todas são noivas; em São Petersburgo, todos são noivos".

Se Gógol relacionava Moscou e São Petersburgo com um grau de parentesco típico de mãe e filho, outro escritor russo, Mikhail Zagóskin, as caracterizou como irmã mais velha e irmão mais novo. No ensaio intitulado Dois Caracteres, publicado em 1841, Zagóskin relata as diferenças entre os dois. A irmã é mais velha, de personalidade forte, porém receptiva; desleixada, porém afetuosa:

Basta dar uma olhada nela para ter certeza de seu completo ódio por qualquer uniformidade e simetria. Olhem para o seu adorno na cabeça que mistura! Que junção de cores vivas, que não possuem entre si nenhuma harmonia! Que estranha combinação do velho com o novo! (Américo, 2011, p. 221).

Enquanto o irmão é caracterizado como organizado, disciplinado, porém frio, calculista. Nas palavras de Zagóskin:

O irmão anda muito a pé, não tem medo do aperto e gosta de viver no alto: ele não se assusta com escadas e nem com duzentos degraus. É difícil encontrar uma pessoa que aprecie tanto limpeza e asseio quanto ele. Da mesma forma ele gosta em excesso de uniformidade e simetria (Américo, 2011, p. 220).

Apesar das diferenças, os irmãos se complementam, afinal, pertencem à mesma família. Zagóskin prima pela distância da narração, não tecendo elogios ou críticas a um modo de ser ou a outro; apenas são apresentadas as concepções e comportamento de ambos, de modo que se tornam agudas e visíveis as diferenças.

De acordo com Serguei Nekliúdov, no século XX a inclinação para visualizar Moscou como uma moça, noiva, tende a vencer: a cidade passa a ser comparada, cada vez mais, com uma jovem e bela mulher. Provavelmente, uma das poesias mais ternas dedicadas a Moscou no período antes da Revolução de 1917 é a de Aleksandr Blok, “Manhã em Moscou”, de 1909:

Amo-te, minha panna,

Minha juventude despreocupada

E a ternura transparente do Kremlin

Nessa manhã é como o teu encanto (Américo, 2011, p. 155). 
Aqui Moscou é novamente comparada à imagem da mulher - dessa vez, à mulher amada. Chama atenção o epíteto "ternura do Kremlin": dificilmente podemos imaginar alguém usando essa comparação após a revolução.

Já no ciclo Versos sobre Moscou, de Marina Tsvietáeva (1916), nota-se o paralelo entre a cidade rejeitada por Pedro, o Grande, e a mulher rejeitada pelo homem:

Sobre a cidade rejeitada por Pedro

Estrondou o trovão dos sinos.

A maré alta retumbante caiu

Diante da mulher rejeitada por ti.

Ao Czar Pedro e a você, czar, glória!

Mas acima de vocês, czares: os sinos.

Enquanto eles retumbam do azul -

É incontestável a primazia de Moscou (Américo, 2011, p. 159).

Logo após a revolução, em 1918, Moscou volta a ser capital e passa a ser vista como uma representação de toda a União Soviética. Acompanhando o novo país, a capital também rejuvenesce. No romance inacabado Moscou Feliz, de 1936, escrito por Andrei Platónov, Moscou é igualmente o nome da personagem principal. A heroína Moscou Tchesnóva é uma bela jovem pela qual se apaixonam todos os homens. Entretanto, ela não se interessa pelo amor, aspirando a grandes feitos que mudassem o futuro do país: salta de paraquedas e participa da construção do metrô, na qual, em decorrência de um acidente, perde uma das pernas. As relações entre a Moscou-cidade e Moskvá-mulher foram delineadas por Serguei Nekliúdov no ensaio "O corpo de Moscou: a Questão da Imagem da 'Cidade-Mulher' na Literatura Russa”.

O tema de Moscou no romance de Platónov se duplica, a cidade está personificada na figura da heroína, enquanto ela mesma adquire "conotações de cidade", as imagens da mulher e da cidade estão combinadas e entrelaçadas, embora o autor evite colisões diretas (Nekliúdov, 2005).

De acordo com Nekliúdov, se tirarmos do contexto do romance algumas frases dedicadas à cidade ou à mulher, elas se tornam ambíguas e podem ser relacionadas às duas: 
Moscou não tinha noção nenhuma do quanto era famosa: e o que isso representava (1). [Ele] desfrutava de Moscou independente; ele já a amava como uma pura verdade e, por causa da sua felicidade, a via de modo obscuro e incorreto (2). O coração dele sofria por Moscou... (3). Ela, Moscou, vivia independente, sem se importar com o trabalho, o destino, as perseguições do mundo, toda bobagem, tudo, como uma planta que se mantém viva pelo calor interno, sob o vento, tempestade e neve. Ela se separou em nome da união com o futuro (4) (Nekliúdov, 2005).

Por meio dessas citações, torna-se claro que Platónov "brinca" propositalmente com esse sentido ambíguo que pode ser remetido tanto à cidade quanto à mulher. A capital soviética aparece no romance como um ser vivo, sendo possível até mesmo ouvir os batimentos do seu coração. A Moscou-mulher, assim como a cidade, deseja transformar o mundo e as pessoas ao seu redor, por isso recusa o amor do engenheiro Sartorius e pede que ele trabalhe intensamente em grandes invenções. A capital soviética também só aceita os novos habitantes em troca de trabalho e muitos esforços: essa necessidade da concessão do direito de morar em Moscou em "troca" de trabalho para o bem da sociedade foi relatada décadas depois em um dos filmes mais populares da União Soviética: Moscou Não Acredita em Lágrimas, de 1980, do diretor Vladímir Menchov. O filme apresenta a Moscou dos anos 50 e três amigas oriundas da província que vieram "tentar a vida" na capital soviética. Cada uma delas encontra o próprio caminho para "conquistar" a cidade. Assim, a heroína principal, Ekaterina, de simples operária torna-se diretora de uma grande indústria e encontra o verdadeiro amor. $\mathrm{O}$ filme gozou de tanta fama que, de acordo com Vladímir Menchov, em 1985, o então presidente dos Estados Unidos, Ronald Reagan, antes de encontrar-se com Mikhail Gorbatchiov, assistiu a ele pelo menos oito vezes para entender melhor "a misteriosa alma russa".

Essa comparação entre a capital e o jovem país soviético, ambos relacionados à imagem feminina, pode ser observada com muita clareza nos versos de Vassíli Lébedev-Kumátch "Moscou de Maio" (1937), que se tornou letra de uma das canções mais populares da toda a União Soviética:

A manhã pinta com uma cor terna

As paredes do antigo Kremlin,

Acorda com o amanhecer

Toda a terra soviética. 
$[\ldots]$

Bom dia, querida cidade,

Coração da minha pátria!

$[\ldots]$

Efervescente,

Poderosa,

Não derrotada por ninguém,

Meu país,

Minha Moscou,

Você é a mais amada! (Américo, 2011, p. 179).

\section{Conclusões}

Embora seja impossível esgotar todas as obras da literatura russa em que Moscou é associada à figura feminina, o intuito do presente artigo era apresentar um panorama geral desse tema para a literatura e a cultura russa.

Vale observar ainda que a imagem da cidade como mulher é universal e pode ser encontrada também na literatura brasileira. Como prova disso, citaremos um trecho do poema Paulicéia Desvairada, de Mario de Andrade, em que o poeta descreve suas relações com a cidade de São Paulo como que estabelecidas entre um noivo e uma noiva:

Paulicéia, minha noiva... Há matrimônios assim...

Ninguém os assistir-nos-á jamais! (Andrade, 1993, p. 87)

Infelizmente, a análise da imagem das cidades na literatura brasileira extrapola a proposta do presente artigo, portanto concluo apenas que esse tipo de abordagem oferece um vasto campo de possíveis paralelos culturais e tipológicos.

Conforme análise, a forma como ambas as capitais são retratadas na literatura russa representa uma intensa correlação que também pode ser chamada de simbiose: são assim as relações entre mãe e filho ou irmã e irmão. Desse modo, as duas cidades se completam; uma não existe sem a outra.

\section{Referências bibliográficas}

Américo, Edelcio. Os Textos de Moscou e São Petersburgo como Reflexo da Identidade Nacional Russa. Tese de doutorado. FFLCH/USP, São Paulo: 2011.

Andrade, Mario de. "Paulicéia Desvairada". In: Poesias Completas. Belo Horizonte/ Rio de Janeiro: Villa Rica, 1993. 
Berman, Marshall. Tudo que É Sólido Desmancha no Ar. São Paulo: Editora Schwarcz Ltda., 2010.

Freidenberg, Olga. "Viézd v Ierussalím na Osslíe. Iz Ievánguelskoi Mifológuii" ("Entrada na Jerusalém de Burro. Da Mitologia Evangélica”). In: Mif e Literatura (Mito e Literatura). Moscou: Nauka, 1978.

Gúlin, A. V. "Moskva 1812 Goda v Romane L. N. Tolstogo Voina i Mir" (“A Moscou de 1812 no Romance de L. N. Tolstói Guerra e Paz). In: Moskva v Russkoi i Mirovoi Literature (Moscou na Literatura Russa e Mundial). Moscou: Nasledie, 2000.

Iussupov, K. "Dialóg Stolits v Istorítcheskom Dvijénii" ("Diálogo das Capitais no Movimento Histórico"). In: Pro et Contra Moskvá-Peterburg (Pro et Contra MoscouPetersburgo). Moscou: RGKHI, 2000.

Lótman, Iúri. "Simvólika Peterburga i Problemy Semiótiki Góroda" ("Simbologia de São Petersburgo e os Problemas da Semiótica da Cidade”). In: Istoria i Tipológuia Rússkoi Kultury (História e Tipologia da Cultura Russa). São Petersburgo: Iskusstvo, 2002, 208-221.

Nekliúdov, Serguei. “Tielo Moskvy. K Vopróssu ob Obraze 'Jiénshiny-Góroda' v Rússkoi Littérature” (“O Corpo de Moscou: a Questão da Imagem da 'Cidade-Mulher' na Literatura Russa”). In: Tielo v Rússkoi Kultúre (O Corpo na Cultura Russa). Moscou: NLO, 2005, 361-385.

Tolstói, Liev. Guerra e Paz. São Paulo: Cosac Naify, 2011. Trad. Rubens Figueiredo. Toporov, Vladimir. "Peterburg i Peterbúrgskii Tekst Rússkoi Literatury" ("Petersburgo e o Texto de São Petersburgo da Literatura Russa”). In: Peterbúrgskii Tekst Rússkoi Literatury (Texto Petersburguês da Literatura Russa). São Petersburgo: Iskusstvo, 2003.

. “Tiékst 'Góroda-Diévy’ i 'Góroda-Bludnítsy’ v Mifologuítceskom Aspiékte” (“Texto da 'Cidade-Virgem' e 'Cidade-Pecadora' no Aspecto Mitológico”). In: Issliédovania po Struktúre Tiéksta (Estudos de Estrutura de Texto). Moscou: 1987, 121132.

Vólkov, Guénrikh. Mir Púchkina (O Mundo de Púchkin). Moscou: Molodáia Gvárdia, 1989.

Vólkov, Solomon. São Petersburgo, uma História Cultural. Rio de Janeiro: Record, 1997. 